\title{
Free Access: Sistema Colaborativo para o Mapeamento de Locais com Acessibilidade para Pessoas com Mobilidade Reduzida
}

\author{
Kleitianne S. de Macêdo ${ }^{1}$, Amanda dos S. Bernardo', Kadja Alleska S. de Lima ${ }^{1}$, \\ Edmilson Barbalho C. Neto' ${ }^{1}$, Alba Sandyra B. Lopes ${ }^{1}$ \\ ${ }^{1}$ Instituto Federal de Educação, Ciência e Tecnologia do Rio Grande do Norte (IFRN) - \\ Campus Natal/Zona Norte - Natal - RN - Brasil \\ \{kleitianne.silva, kadja.alleska, \\ amanda.santos\} descolar.ifrn.edu.br, \{alba.lopes, \\ edmilson.campos\} @ifrn.edu.br
}

Resumo: A acessibilidade é um direito de todos os cidadãos garantido pela Constituição, contudo este direito nem sempre é respeitado. Aliado a este fator, a falta de informação sobre ambientes devidamente acessíveis acaba sendo um dos aspectos que inviabiliza a movimentação de indivíduos que possuem deficiência física elou mobilidade reduzida. Este projeto apresenta um aplicativo e sistema web colaborativo que mapeia locais com acessibilidade para pessoas com mobilidade reduzida, objetivando facilitar o acesso de pessoas com baixa mobilidade a todos os tipos de ambiente e ainda oportunizar sua maior inserção na sociedade.

Palavras-chave: acessibilidade; mobilidade reduzida; sistema web.

\section{Introdução}

$\mathrm{O}$ direito à acessibilidade no Brasil é assegurado pela Lei Brasileira $\mathrm{n}^{\mathrm{o}}$ 13.146, que instituiu o Estatuto da Pessoa com Deficiência (BRASIL, 2015) no país. No qual estabelece, em seu Art. 53, o direito à "pessoa com deficiência ou com mobilidade reduzida viver de forma independente e exercer seus direitos de cidadania e de participação social”. Indivíduos que apresentam algum tipo de deficiência física possuem limitações que vão da dificuldade de execução de alguma atividade simples até sua locomoção de um lugar a outro (PAGLIUCA; VASCONCELOS, 2006). O censo 2010 (IBGE, 2010), aponta que $23,9 \%$ dos brasileiros possuem algum tipo deficiência, sendo $7 \%$ deficiência motora. Dentro desse total, aproximadamente $27,86 \%$ moram no Rio Grande do Norte, o que corresponde a 882.022 norte-rio-grandenses com deficiência física.

Em contrapartida, mesmo sendo obrigatório por lei, são poucos os estabelecimentos que possuem condições necessárias de receber essas pessoas. Portas pequenas, banheiros inadequados, falta de rampas e de vagas de estacionamento são alguns dos fatores que inviabilizam o livre acesso desses cidadãos. Outro fator agravante é a falta de informação sobre locais devidamente equipados e adequados para receber essas pessoas, o que acarreta no desestímulo por parte desses indivíduos de irem a determinados lugares ou até mesmo de saírem de suas casas.

Com intuito de melhorar a qualidade de vida e a autonomia de pessoas que possuem deficiência física e/ou mobilidade reduzida, o presente projeto propõe $\mathrm{o}$ desenvolvimento de um sistema web e aplicativo colaborativo que mapeia locais com acessibilidade. O FreeAccess (Acesso Livre), é uma proposta que visa auxiliar a introdução dos indivíduos com mobilidade reduzida na sociedade e estimular os estabelecimentos a se tornarem acessíveis, promovendo o bem-estar a todos. 


\section{Metodologia}

Para o melhor desenvolvimento desse projeto foi realizado um estudo nas seguintes etapas:

(i) Estudo acerca da mobilidade e acessibilidade; onde foi realizada uma análise para compreender melhor os conceitos de acessibilidade e mobilidade, e a partir disso, foi elaborado um questionário visando as principais dificuldades que pessoas que possuem baixa mobilidade enfrentam ao chegarem em locais sem acessibilidade;

(ii) Pesquisas com o público-alvo; foi feita a aplicação de questionários in-loco com cerca de 15 pessoas que possuíam deficiência física e/ou mobilidade reduzida, na ADEFERN (Associação de Deficientes Físicos do Rio Grande do Norte), afim de caracterizar os principais problemas encontrados por elas ao chegarem em locais sem acessibilidade. Além de, também, investigar se esses indivíduos possuem algum meio de saber previamente se um local possui as condições necessárias para recebê-la.

(iii) Pesquisa realizada em estabelecimentos para análise e avaliação da acessibilidade; no qual foi feito um check-list para análise da acessibilidade dos locais, verificando a presença de determinados elementos essenciais para a melhor locomoção de pessoas com baixa mobilidade como: portas largas, ausência de escadas, vagas de estacionamento reservadas, banheiros acessíveis, distância ideal entre mesas e cadeiras, etc.

(iv) Pesquisa de aplicativos ou sistema que tivessem finalidades semelhantes ao nosso.

\section{Resultados e discussões}

Após a análise dos resultados obtidos, verificamos que grande parte dos entrevistados relatou não possuir nenhum meio de informação prévia a respeito da acessibilidade dos locais - representado na Figura 1.

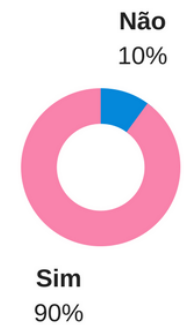

Figura 1: Pessoas que utilizam algum meio para obter informações prévias sobre a acessibilidade dos locais.

Realizamos ainda uma pesquisa para identificarmos se já existia no mercado algum sistema com fins semelhantes, e através dela encontramos os seguintes resultados: o aplicativo Turismo Acessível, que se restringe apenas a realizar o mapeamento de pontos turísticos e o Guia de Rodas, que está disponível apenas como aplicativo e sofre alguns problemas de usabilidade.

Posterior a esse estudo, fizemos uma análise e formulamos uma solução proposta, que consiste na criação de um sistema web responsivo, também em versão de aplicativo: o FreeAccess (Acesso Livre), no qual, possibilitará o mapeamento e avaliação da acessibilidade de diversos locais na cidade, objetivando indicar quais os requisitos de acessibilidade que são atendidos por cada um desses locais. Dessa forma, o usuário poderá procurar locais no mapa e antecipadamente saber se ele terá ou não a devida acessibilidade para recebê-lo. 
No desenvolvimento do sistema foi usado HTML5, CSS3 e o framework Bootstrap para parte visual. A linguagem de programação utilizada foi PHP, juntamente com o framework CodeIgniter para o desenvolvimento back end. Além disso, utilizou-se a base de dados MySQL e a API Google Places, serviço disponibilizado pela Google. Dessa forma, qualquer local que exista no Google Maps poderá ser adicionado em nosso banco de dados. A figura 2 apresenta a tela inicial, onde o usuário poderá buscar locais a serem consultados e avaliados.

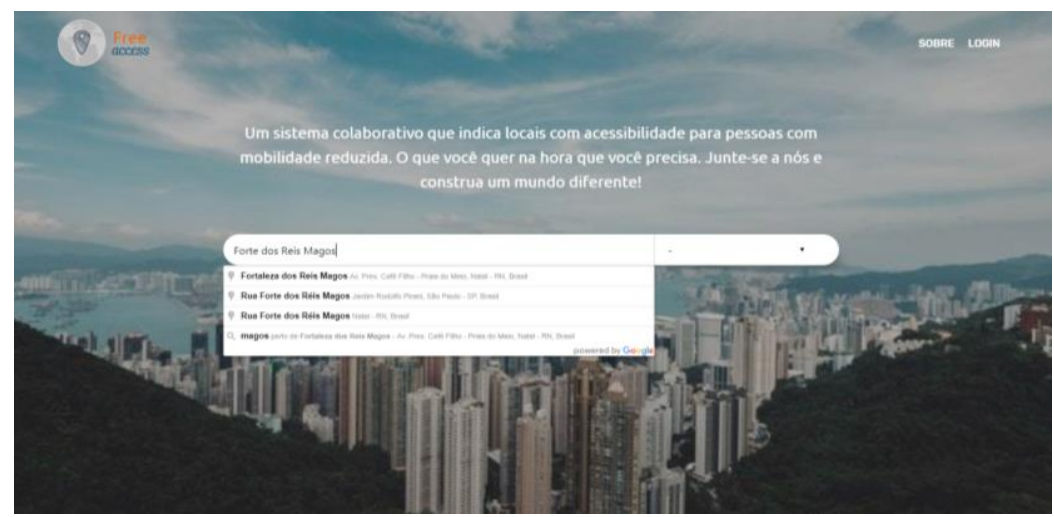

Figura 2: Tela inicial de busca de locais.

Na tela de resultados será mostrado ao usuário as informações sobre o local e mais abaixo as avaliações que o mesmo obteve em cada um dos requisitos, como mostra na figura 3. As informações sobre o local, como: nome, endereço, telefone, imagem, tipo e coordenadas são recuperadas da API Google Places.

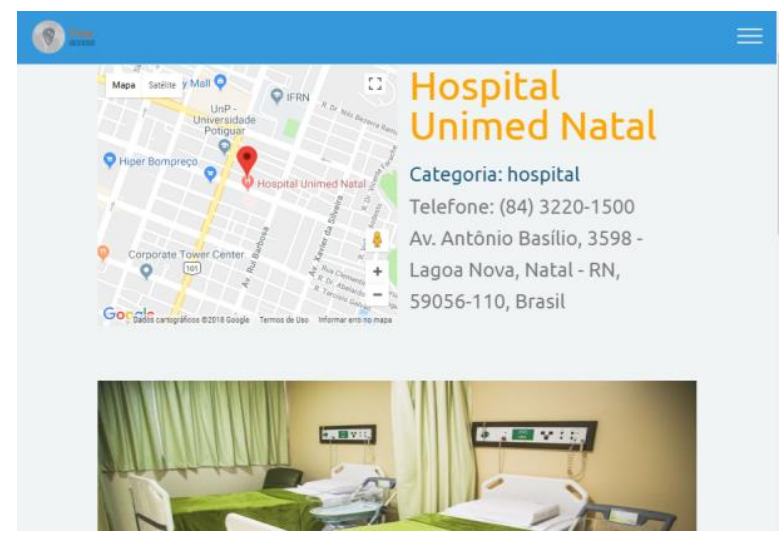

Figura 3: Página de resultados com informações dos locais.

No sistema também é possível que o usuário realize avaliações dos locais que visitar, respondendo algumas perguntas de forma simples. A figura 4 apresenta um pouco da tela de avaliação de um local.

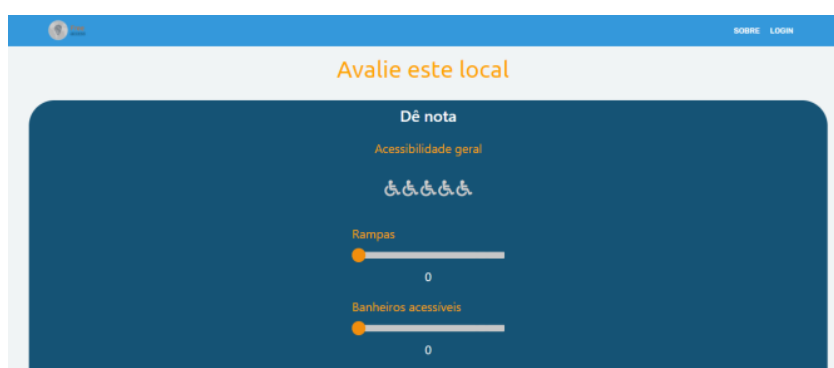

Figura 4: Tela de avaliação de um local selecionado. 
$\mathrm{Na}$ avaliação os usuários podem dar notas de 0 a 5 para cada um dos itens de acessibilidade, tendo 0 como péssimo e 5 como excelente. Cada item apresentado foi extraído das normas da ABNT NBR 9050:2015. O sistema possui também a sessão de ranking, que mostra os lugares que foram melhores avaliados pelos usuários, apresentando um card com breves informações sobre o local. Para determinar os locais que entram no ranking, são levadas em consideração as avaliações de cada requisito que esse lugar obteve. A partir disso, é feita uma média e é recuperado do banco os 3 lugares com as maiores notas.

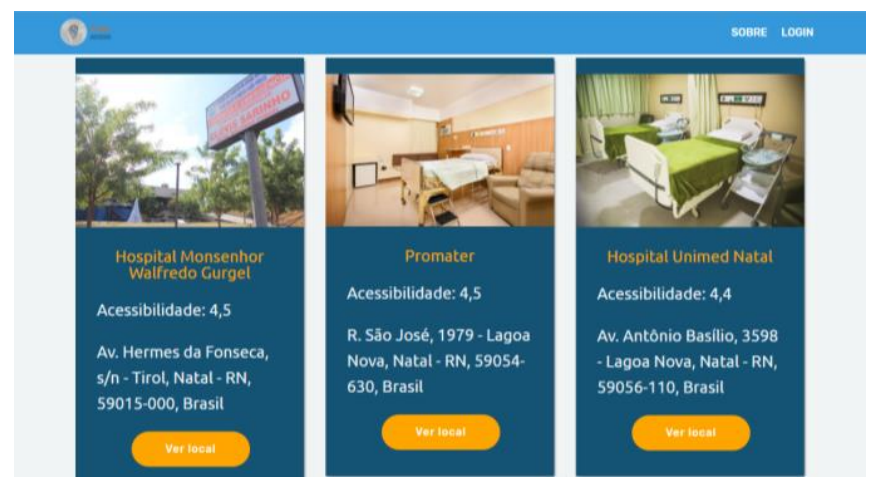

Figura 5: ranking dos locais melhor avaliados.

Ademais, visando abranger a utilização do sistema a um maior número de usuários, ele está sendo desenvolvido de forma a ser responsivo e se adaptar a qualquer dispositivos, sendo eles computadores, tablets, notebooks ou smartphones. O sistema já está hospedado em um servidor web (fases.ifrn.edu.br/freeaccess) e disponível para download na loja de aplicativos Android, a Play Store.

\section{Considerações Finais}

O presente projeto apresentou uma proposta de sistema web colaborativo para auxiliar indivíduos com mobilidade reduzida a encontrarem locais acessíveis. Espera-se que sua utilização possa auxiliar essas pessoas a exercerem sua cidadania e participação social, proporcionando-lhes uma melhor autonomia e qualidade de vida, além de impulsionar sua maior inserção no âmbito social. Pretende-se ainda, realizar melhorias e atualizações, como também a validação do sistema com o público-alvo.

\section{REFERÊNCIAS BIBLIOGRÁFICAS}

ABNT - ASSOCIAÇÃO BRASILEIRA DE NORMAS TÉCNICAS. NBR 9050:2015: Acessibilidade a edificações, mobiliário, espaços e equipamentos urbanos. 5 ed. São Paulo: Moderna, 2015. 148 p.

BRASIL. Assembleia Legislativa. Constituição (2015). Lei Brasileira de Inclusão da Pessoa Com Deficiência no 13.146, de 06 de julho de 2015. da Acessibilidade. Brasília, DF, Disponível em: < https://goo.gl/FuqDSd >. Acesso em: 03 ago. 2016.

PAGLIUCA, Lorita Marlena Freitag; VASCONCELOS, Luciana Rodrigues. MAPEAMENTO DA ACESSIBILIDADE DO PORTADOR DE LIMITAÇÃO FÍSICA A SERVIÇOS BÁSICOS DE SAÚDE. Ceará: Esc Anna Nery R Enferm, 2006. Demarcation of the accessibility of the handicapped to a basic health services. Disponível em: <https://goo.gl/JtvqH2>. Acesso em: 27 maio 2016. 